\title{
Leaching assessment of soil stabilised with hydraulic binders
}

\author{
DENEELE DIMITRI ${ }^{1,2^{*}}$, RAZAKAMANANTSOA ANDRY,1
}

${ }^{1}$ GERS-LEE, Université Gustave Eiffel, IFSTTAR, F-44344 Bouguenais, France $(*$ correspondence: dimitri.deneele@univ-eiffel.fr)

${ }^{2}$ Université de Nantes, CNRS, Institut des Matériaux Jean Rouxel, F-44322 Nantes, France

Soil stabilisation with hydraulic binders is a technique to refine and improve the engineering properties of soils such as mechanical strength, permeability, compressibility, plasticity, etc. The context of saving natural resources and their limited consumption induces the question of durability of treated soil structures, related to stability, or long term physicochemical evolution of soils in their service environment [1]. The present work aims at i) providing information on the long term physicochemical behaviour of lime and cement-treated soils subjected to leaching, and ii) assessing if leaching could be detrimental to the durability of treated-soil.

A multiscale approach was implemented and the mechanical, microstructural and physicochemical changes investigated. The mechanical properties of the treated soil are strongly affected by the microstructural organization induced by binders addition. From a combined multi-scale approach and geochemical modeling, we can claim that the soil behaviour is governed by its initial mineralogical composition, which influence its microstructure and the C-S$\mathrm{H}$ leachability.

[1] Deneele et al. (2016), CBM112, 1032-1040 